\title{
Synthesis and Characterization of Some Metal Complexes of $\mathrm{Cu}(\mathrm{II}), \mathrm{Ni}$ (II), Zn(II), Cd(II), Sn(II), Co(II), Sb(III) AND Fe(III) Containing Bidentate Schiff Base of Smdtc
}

\author{
Abdul Alim', Md. Kudrat-E-Zahan ${ }^{2, ~ *, ~ M d . ~ M a s u q u l ~ H a q u e ², ~ M T H ~ T a r a f d e r ~}{ }^{2}$ \\ ${ }^{1}$ Department of Analytical and Environmental Chemistry, Bangabandhu Sheikh Mujibur Rahman Science and Technology University, \\ Gopalganj, Bangladesh \\ ${ }^{2}$ Inorganic Research Laboratory, Department of Chemistry, University of Rajshahi, Rajshahi, Bangladesh
}

Email address:

kudrat.chem@ru.ac.bd (Md. Kudrat-E-Zahan)

\section{To cite this article:}

Abdul Alim, Md. Kudrat-E-Zahan, Md. Masuqul Haque, MTH Tarafder. Synthesis and Characterization of Some Metal Complexes of Cu(II), $\mathrm{Ni}(\mathrm{II}), \mathrm{Zn}(\mathrm{II}), \mathrm{Cd}(\mathrm{II}), \mathrm{Sn}(\mathrm{II}), \mathrm{Co}(\mathrm{II}), \mathrm{Sb}(\mathrm{III})$ AND Fe(III) Containing Bidentate Schiff Base of Smdtc. Science Journal of Chemistry.

Vol. 3, No. 3, 2014, pp. 35-39. doi: 10.11648/j.sjc.20150303.11

\begin{abstract}
A series of transition metal complexes of $\mathrm{Cu}(\mathrm{II}), \mathrm{Ni}(\mathrm{III}) \mathrm{Zn}(\mathrm{II}), \mathrm{Cd}(\mathrm{II}), \mathrm{Co}(\mathrm{II}), \mathrm{Sb}(\mathrm{III})$ and $\mathrm{Fe}(\mathrm{III}) \mathrm{Containing}$ Bidentate Schiff base, [ $N^{I}$-(4-chloro-benzylidene)-hydrazecarbodithioicacid methyl ester] derived from the condensation of Smethyldithiocarbazate and P-chlorobenzaldehyde were synthesized and characterized by IR, UV- Vis., and some physical measurements. IR spectral studies show the binding sites of the Schiff base ligand with the metal ion. Molar conductance data and magnetic susceptibility measurements give evidence for monomeric and neutral nature of the complexes.
\end{abstract}

Keywords: Transition Metal Complex, SMDTC, P-chlorobenzaldehyde, Schiff Base

\section{Introduction}

The Chemistry of Schiff-base complexes has attracted a great deal of attention ever since Pfeiffer carried out his pioneering research in the 1930's. The Schiff-base ligands are derived by the condensation of a primary amine and an active carbonyl group, and contain the azomethine group $(-\mathrm{CH}=\mathrm{N}-$ or $>\mathrm{C}=\mathrm{N}-$ :). These bases can be effective chelating agents in either the carbonyl compound as the amine or both contain potentially coordinating functional groups near the site of condensation. Schiff-bases may act as mono-, di-, tri-, or tetradentate ligands depending on the number of coordinating atoms present in the molecule and can form generally five or six membered chelate rings upon reaction with a metal ion. Among many schiff-bases the dithiocarbazate (NH2NHCS2) and its substituted derivatives have been investigated as ligand for a long time too [1-5]. These compounds have received much attention for further studies because i) they provide an interesting series of ligands whose properties can be greatly modified by introducing different organic substituents, thereby causing a variation of ultimate donor properties (ii) the interaction of these donor to metal ions gives complexes of different geometries and properties and (iii) these complexes are potentially biologically active [6-9].
Recently, we studied few mixed ligand complexes containing heterocyclic amine as secondary ligands and few Schiff base containing complexes [10-19]. In this paper, we describe synthesis of a Schiff base [ $N^{I}$-(4-chloro-benzylidene)-hydrazecarbodithioicacid methyl ester], formed by condensing cinnamaldehyde with Smethyldithiocarbazate and its complexation with $\mathrm{Mn}(\mathrm{II})$, $\mathrm{Fe}$ (III) $\mathrm{Co}(\mathrm{II}), \mathrm{Ni}(\mathrm{II}), \mathrm{Cu}(\mathrm{II})$ and $\mathrm{Sb}$ (III).

\section{Experimental}

\subsection{Reagents and Chemicals}

All the reagents used were of analar or chemically pure grade. Solvents were purified and dried according to standard procedures.

\subsection{Physical Measurements}

The melting or decomposition temperatures of all the prepared metal complexes were observed in an electro thermal melting point apparatus model No.AZ6512. The SHERWOOD SCIENTIFIC Magnetic Susceptibility Balance was used for the present investigation. Infrared spectra as $\mathrm{KBr}$ disc were recorded in a SIMADZU FTIR-8400 (Japan) 
infrared spectrophotometer, from 4000-400 $\mathrm{cm}^{-1}$. The absorbances of the complexes were recorded on SHIMADZU Spectrophotometer.

\section{Preparation}

\subsection{Preparation of the Ligand S-Methyldithiocarbazate (SMDTC): Reaction}

Procedure: SMDTC was prepared by the method of Akbar Ali [3].<smiles>CC(=S)NN</smiles>

SMDTC

$$
\mathrm{NH}_{2} \mathrm{NH}_{2} \cdot \mathrm{H}_{2} \mathrm{O}+\mathrm{CS}_{2}+\mathrm{KOH} \longrightarrow \mathrm{NH}_{2}-\mathrm{NH}-\mathrm{C}_{\mathrm{S}^{\prime \prime} \mathrm{K}^{+}}^{\mathrm{S}}
$$

KDTCA (brown oil)

\subsection{Preparation of the P-chlorobenzaldehyde Schiff base of SMDTC, \\ [N'-(4-chloro-benzylidene)-hydrazecarbodithioicacid methyl ester] (NS)}

SMDTC (1.22 g, $10 \mathrm{mmol})$ was dissolved in hot absolute ethanol (30-40 ml). To this solution the equimolar amount ofP-chlorobenzaldehyde in hot absolute ethanol $(20 \mathrm{ml})$ was added and the mixture was heated for $20 \mathrm{~min}$ and then cooled. The White precipitate, which has formed was separated and dried in vacuo over anhydrous $\mathrm{CaCl}_{2}$. (m.p. $152^{\circ} \mathrm{C}$ ).

\subsection{General Method for the Preparation of the Complexes with IN $N^{I}$-(4-chloro-benzylidene)-hydrazecarbodithioicacid methyl ester] (NS)}

Metal salt with hydrate $\left[\mathrm{Cu}\left(\mathrm{NO}_{3}\right)_{2} .3 \quad \mathrm{H}_{2} \mathrm{O}\right](0.241 \mathrm{~g}, 1$ mmol); [ $\left.\mathrm{Ni}\left(\mathrm{NO}_{3}\right)_{2} .6 \mathrm{H}_{2} \mathrm{O}\right](0.290 \mathrm{~g}, 1 \mathrm{mmol})$; $\left[\mathrm{Zn}\left(\mathrm{NO}_{3}\right) 2.6\right.$ $\mathrm{H}_{2} \mathrm{O}$ ] $(0.297 \mathrm{~g}, 1 \mathrm{mmol})$; [ $\left.\mathrm{CoCl}_{2} 6 \mathrm{H}_{2} \mathrm{O}\right](0.238 \mathrm{~g} 1 \mathrm{mmol})$ was dissolved in absolute ethanol $(15 \mathrm{ml})$. The Schiff base, [ $\mathrm{N}^{I}$-(4-chloro-benzylidene)-hydrazecarbodithioicacid methyl ester] $(0.24477 \mathrm{~g}, 1 \mathrm{mmol})$ in hot absolute ethanol (50 $\mathrm{ml}$ ) was added to the metal solution. The mixture was then refluxed for $30 \mathrm{mins}$ and then cooled. The precipitate was filtered off and washed with hot ethanol and dried in vacuo over anhydrous $\mathrm{CaCl}_{2}$.

$$
\begin{gathered}
\mathrm{M}\left(\mathrm{NO}_{3}\right)_{2} \cdot n \mathrm{H}_{2} \mathrm{O}+\mathrm{NS} \rightarrow\left[\mathrm{M}(\mathrm{II})(\mathrm{NS})_{2}\right], \\
\mathrm{M}^{\prime} \mathrm{Cl}_{2} \cdot \mathrm{nH}_{2} \mathrm{O}+\mathrm{NS} \rightarrow\left[\mathrm{M}^{\prime}(\mathrm{II})(\mathrm{NS})_{2}\left(\mathrm{H}_{2} \mathrm{O}\right)_{2}\right]
\end{gathered}
$$

Where, $\mathrm{M}=\mathrm{Cu}(\mathrm{II}), \mathrm{Ni}(\mathrm{II})$ and $\mathrm{Zn}(\mathrm{II}) ; \mathrm{M}^{\prime}=\mathrm{Co}(\mathrm{II}), \mathrm{NS}^{\prime}=$ P-Chlorobenzaldehyde Schiff base of SMDTC.

\section{Results and Discussion}

\subsection{Physical Properties and Molar Conductance}

Physical properties of the complexes were given in Table 1. The analytical data were in good agreement with the proposed empirical formula of the present complexes. The conductance values of the complexes reveal that these were non electrolyte

\begin{tabular}{|c|c|c|c|c|}
\hline Complexes & Colour & $\begin{array}{l}\text { Melting point or decomposition } \\
\text { temperature }\left( \pm 5^{\circ} \mathrm{C}\right)\end{array}$ & $\begin{array}{l}\text { Molar conductance } \\
\left(\mathrm{ohm}^{-1} \mathrm{~cm}^{2} \mathrm{~mol}^{-1}\right)\end{array}$ & $\begin{array}{l}\mu_{\text {eff }} \\
(B . M)\end{array}$ \\
\hline SMDTC & White & 81 & 2.45 & - \\
\hline$[\mathrm{NS}]$ & White & 152 & 2.25 & - \\
\hline$\left[\mathrm{Cu}(\mathrm{II})(\mathrm{NS})_{2}\right]$ & Greenish brown & 188 & 3.28 & 1.98 \\
\hline$\left[\mathrm{Ni}(\mathrm{II})(\mathrm{NS})_{2}\right]$ & Golden brown & 240 & 5.19 & Dia \\
\hline$\left[\mathrm{Zn}(\mathrm{II})(\mathrm{NS})_{2}\right]$ & Light yellow & 218 & 3.58 & Dia \\
\hline$\left[\mathrm{Co}(\mathrm{II})(\mathrm{NS})_{2}\left(\mathrm{H}_{2} \mathrm{O}\right)_{2}\right]$ & Reddish black & 220 & 2.50 & 3.94 \\
\hline
\end{tabular}
in nature [3].

Table 1. Analytical data and physical properties of the complexes.

Where, NS $=\left[N^{I}\right.$-(4-chloro-benzylidene)-hydrazecarbodithioicacid methyl ester $]$

\subsection{R Studies}

SMDTC showed all the characteristic bands as reported in the literature [3, 19]. The IR spectrum of SMDTC (Table 2) showed strong intensity bands at $3415 \mathrm{~cm}^{-1}$ and 3262 $\mathrm{cm}^{-1}$ (which were assigned to the asymmetric $\mathrm{v}(\mathrm{N}-\mathrm{H})$ and symmetric $\mathrm{v}(\mathrm{N}-\mathrm{H})$ modes of the $\mathrm{NH}_{2}$ group, respectively. The $\mathrm{v}(\mathrm{C}=\mathrm{S})$ band for SMDTC appeared at $1006 \mathrm{~cm}^{-1}$.SMDTC had a proton adjacent to the thione group. The thione group was relatively unstable in the monomeric form and tends to turn to the more stable C-S bond by enethiolisation if there was at least one proton adjacent to the thione group. The IR spectrum of Schiff bases did not display v $(\mathrm{S}-\mathrm{H})$ bands at around $2570 \mathrm{~cm}^{-1}$ indicating that in the solid state it remained in the thioketo forms. However, in solution, both the thion and thiolo tautomeric forms are possible.In alkaline medium, the ligand deprotonates by the loss of the proton from the sec. $\mathrm{NH}$ group appearance of $\mathrm{v}(\mathrm{C}=\mathrm{N})$ and disappearance of $\mathrm{v}(\mathrm{N}-\mathrm{H})$ will indicate deprotonation. This will be further evident from the absence of $\mathrm{v}(\mathrm{C}=\mathrm{S})$ in the complexes. The Schiff-base exist in tautomeric froms through the loss of thilo protons. Schiff base behaved as uninegatively charged bidented ligands by co-ordinating through the thiolo sulfur and the azomethine nitrogen.

The IR spectrum (Table 2) of the Schiff base showed strong bands at $3106 \mathrm{~cm}^{-1}$. This was attributed to the secondary amine $\mathrm{v}(\mathrm{N}-\mathrm{H})$ mode of the free ligands. The thione groups are 
relatively unstable in the monomeric form and tend to turn to the more stable thiolo forms by enethiolization in solution. The absence of $\mathrm{v}(\mathrm{S}-\mathrm{H})$ absorbance at approximately $2570 \mathrm{~cm}^{-1}$ indicates that in the solid state, the bases exist primarily in the thione form. The disappearance of $\mathrm{v}(\mathrm{N}-\mathrm{H})$ bands in the spectra of the metal complexes suggests deprotonation and consequent co-ordination through the thiolate anions. The Schiff base also showed strong bands at $1596 \mathrm{~cm}^{-1}$. These are assigned to the $\mathrm{v}(\mathrm{C}=\mathrm{N})$ modes for the free ligand. In the metal complexes, this stretching band shifted to lower frequencies, due to the lowering of the $\mathrm{C}=\mathrm{N}$ bond order as a result of the metal-nitrogen bond formation. The Schiff base also showed $\mathrm{v}(\mathrm{C}=\mathrm{S})$ modes at $1038 \mathrm{~cm}^{-1}$. The $\mathrm{v}(\mathrm{C}=\mathrm{S})$ mode observed in the free ligand disappeared in the complexes, thus supporting the above contention of thiolate bonding with metal ions. Consequently the $\mathrm{v}(\mathrm{C}-\mathrm{S})$ mode was observed in the spectra of the complexes supporting thiolate bindings.
The $\mathrm{C}=\mathrm{N}$ stretching vibration in the free NS Schiff base appeared at $1586 \mathrm{~cm}^{-1}$, which upon complexation, shifted towards lower frequency regions, at $1584 \mathrm{~cm}^{-1}$ (Table 2). This lowering of $\mathrm{C}=\mathrm{N}$ stretching mode on complexation supported coordination through nitrogen atom. The mode of the free Schiff base appeared at $1038 \mathrm{~cm}^{-1}$. This band also disappeared in the IR spectra of the metal complexes giving evidence of coordination-through the thilate anion. The Schiff base coordinated to the metal through the thiolate sulphur and the p-nitrogen as evident from the IR spectrum showing bands at $360 \mathrm{~cm}^{-1}$ and $405 \mathrm{~cm}^{-1}$, corresponding to $\mathrm{v}(\mathrm{M}-\mathrm{S})$ and $\mathrm{v}(\mathrm{M}-\mathrm{N})$ stretching modes, respectively.In case of complexes $\left[\mathrm{Ni}(\mathrm{II})(\mathrm{NS})_{2}\right]$ and $\left[\mathrm{Zn}(\mathrm{NS})_{2}\right]$, the IR band at 1573 and 1583 $\mathrm{cm}^{-1}$ was indicated of the presence of coordinated $\mathrm{C}=\mathrm{N}$ bond . The bond stretching vibration $3414 \mathrm{~cm}^{-1}$ for Co(II) complex was indicated the presence of coordinated water molecule.

TabIe 2. Selected infrared spectral bands of the ligands and metal complexes.

\begin{tabular}{|c|c|c|c|c|c|c|c|c|}
\hline Complexes & $\begin{array}{l}\mathrm{v}\left(\mathrm{NH}_{2}\right) \\
\mathrm{cm}^{-1}\end{array}$ & $\begin{array}{l}\mathrm{v}(\mathrm{N}-\mathrm{H}) \\
\mathrm{cm}^{-1}\end{array}$ & $\begin{array}{l}v(C=S) \\
\mathrm{cm}^{-1}\end{array}$ & $\begin{array}{l}v(C=N) \\
\text { cm }^{-1}\end{array}$ & $v(C-S) \mathrm{cm}^{-1}$ & $\begin{array}{l}\mathrm{v}(\mathrm{M}-\mathrm{S}) \\
\mathrm{cm}^{-1}\end{array}$ & $\begin{array}{l}v(M-N) \\
\text { cm }^{-1}\end{array}$ & $\mathrm{v}(\mathrm{OH}) \mathrm{cm}^{-1}$ \\
\hline SMDTC & $\begin{array}{l}3415 \\
3262\end{array}$ & 3154 & 1006 & - & - & - & - & - \\
\hline [NS] & - & 3106 & 1038 & 1596 & - & - & - & - \\
\hline$\left[\mathrm{Cu}(\mathrm{II})(\mathrm{NS})_{2}\right]$ & - & - & - & 1584 & 603 & 360 & 405 & - \\
\hline$\left[\mathrm{Ni}(\mathrm{III})(\mathrm{NS})_{2}\right]$ & - & - & - & 1478 & 612 & 401 & 484 & - \\
\hline$\left[\mathrm{Zn}(\mathrm{II})(\mathrm{NS})_{2}\right]$ & - & - & - & 1519 & 617 & 395 & 455 & - \\
\hline
\end{tabular}

Where, NS $=\left[N^{I}\right.$-(4-chloro-benzylidene)-hydrazecarbodithioicacid methyl ester $]$

\subsection{Magnetic Moment and Electronic Spectra}

The magnetic susceptibility measurement (Table1) showed that the complex $\left[\mathrm{Cu}(\mathrm{II})(\mathrm{NS})_{2}\right]$ was paramagnetic. The greenish brown paramagnetic copper complex gave a magnetic moment of 1.98 B.M corresponding to one unpaired electron. The UV-vis spectrum, of the complex showed d-d-bands at $420 \mathrm{~nm}$ and $325 \mathrm{mn}$, arising from the ${ }^{2} \mathrm{~B}_{1 \mathrm{~g}} \rightarrow{ }^{2} \mathrm{~A}_{1 \mathrm{~g}}$ and ${ }^{2} \mathrm{~B}_{1 \mathrm{~g}} \rightarrow{ }^{2} \mathrm{E}_{1 \mathrm{~g}}$ transitions, respectively, characteristic of a square planer stereochemistry. The intense band at $220 \mathrm{~nm}$ was presumably caused by charge transfer.

The magnetic susceptibility measurement (Table 1) showed that the complex $\left[\mathrm{Ni}(\mathrm{II})(\mathrm{NS})_{2}\right]$ was diamagnetic. For the electronic spectra, the dianiagnetic nature of complex indicated a singlet ground state characteristic of square planer Ni(II). Three bands corresponding to the transitions ${ }^{7}$ ${ }^{1} \mathrm{~A}_{1 \mathrm{~g}} \rightarrow{ }^{1} \mathrm{~A}_{2 \mathrm{~g}}(300 \mathrm{~nm}),{ }^{1} \mathrm{~A}_{1 \mathrm{~g}} \rightarrow{ }^{1} \mathrm{~B}_{1 \mathrm{~g}}(350 \mathrm{~nm})$ and ${ }^{1} \mathrm{~A}_{1 \mathrm{~g}} \rightarrow{ }^{1} \mathrm{E}_{\mathrm{g}}(400$ $\mathrm{nm}$ ) were observed in the electronic spectra of a square-planer nickel(II) complex as expected.

Table 3. Selected electronic spectral data of the complexes.

\begin{tabular}{llll}
\hline Complexes & Band I & Band II & Band III \\
\hline$\left[\mathrm{Cu}(\mathrm{II})(\mathrm{NS})_{2}\right]$ & 220 & 325 & 420 \\
{$\left[\mathrm{Ni}(\mathrm{II})(\mathrm{NS})_{2}\right]$} & 300 & 350 & 400 \\
{$\left[\mathrm{Zn}(\mathrm{II})(\mathrm{NS})_{2}\right]$} & 320 & - & - \\
{$\left[\mathrm{Co}(\mathrm{II})(\mathrm{NS})_{2}\left(\mathrm{H}_{2} \mathrm{O}\right)_{2}\right]$} & 390 & 430 & 560 \\
\hline
\end{tabular}

Where, NS $=\left[N^{I}\right.$-(4-chloro-benzylidene)-hydrazecarbodithioicacid methyl ester]
The cobalt complex $\left.\left[\mathrm{Co}(\mathrm{II})(\mathrm{NS})_{2}\left(\mathrm{H}_{2} \mathrm{O}\right)\right]_{2}\right]$ showed magnetic moments at 3.94 B.M (Table 1) indicative of octahedral geometry. The electronic spectra of these complexes showed three bands 390, 430 and $560 \mathrm{~nm}$ (Table: 4.3). This bands were assigned to the transition, ${ }^{4} \mathrm{~T}_{1 \mathrm{~g}} \rightarrow{ }^{4} \mathrm{~T}_{2 \mathrm{~g}} \quad\left(\mathrm{v}_{1}\right),{ }^{4} \mathrm{~T}_{1 \mathrm{~g}} \rightarrow{ }^{4} \mathrm{~A}_{2 \mathrm{~g}}$ $\left(v_{2}\right),{ }^{4} \mathrm{~T}_{1 \mathrm{~g}} \rightarrow{ }^{4} \mathrm{~T}_{2 \mathrm{~g}}(\mathrm{~F})\left(\mathrm{v}_{3}\right)$, of octahedral Co(II). The complex $\left[\mathrm{Zn}(\mathrm{II})(\mathrm{NS})_{2}\right]$ showed absorption bands at $320 \mathrm{~nm}$ arising from charge transfer transitions. The magnetic susceptibility measurement showed that the complex was diamagnetic in nature. The complex was found to be distorted tetrahedral in geometry. All the above observations indicated that the complexes $\left[\mathrm{Cu}(\mathrm{II})(\mathrm{NS})_{2}\right]$ and $\left[\mathrm{Ni}(\mathrm{II})(\mathrm{NS})_{2}\right]$ had square planar structure with two ligands satisfying the four steriochemical sites, where the complexes $\left[\mathrm{Zn}(\mathrm{II})(\mathrm{NS})_{2}\right]$ was distorted tetrahedral.

\section{Structure of the Complexes}

On the basis of the elemental analysis, conductivity measurements, magnetic moment data, spectroscopic studies and literature review the possible structure of the complexes. 


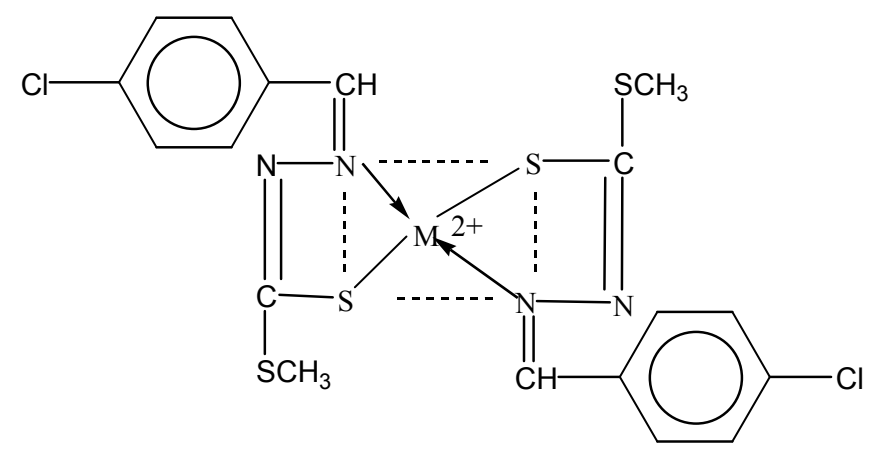

Where, $\mathrm{M}^{2+}=\mathrm{Cu}(\mathrm{II})$ and $\mathrm{Ni}(\mathrm{II})$

Fig. 1. Proposed squareplanner structure of the complex.

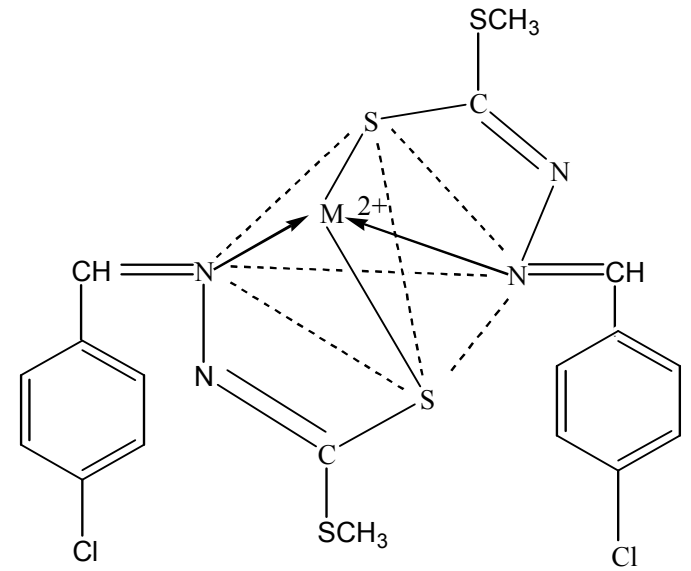

Where, $\mathrm{M}^{2+}=\mathrm{Zn}$ (II) and $\mathrm{Cd}(\mathrm{II})$

Fig. 2. Proposed tetrahedral structure of the complex.

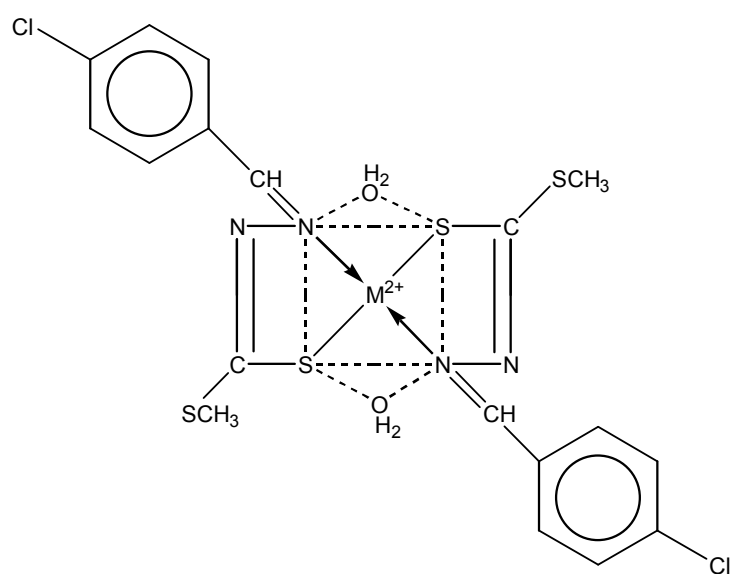

Where, $\mathrm{M}^{2+}=\mathrm{Co}(\mathrm{II})$

Fig. 3.Proposed octahedral structure.

\section{References}

[1] M. Tofazzal H. Tarafder, Manaf A. Ali, N. Saravanan, Wong Y. Weng, Saravana Kumar, N. Umar-Tsafe and Karen A. Crouse. Coordination chemistry and biological activity of two tridentate ONS and NNS Schieff bases derived from S-benzyldithiocarbazate, Transition Metal Chemistry. 2000; 25: 295-298.
[2] Akbar Ali, M., Livingstone, S. E. and Philips, D.J., Metal chelates of dithiocarbazic acid and its derivatives. VI. Antiferromagnetic and ferromagnetic interactions in some copper(II) complexes of salicylaldehyde and acetylacetone Schiff bases derived from s-methyldithiocarbazate, Inorg. Chim. Acta.1973; 7: 179-186.

[3] Akbar Ali, M., Livingstone, S. E. and Philips, D.J., Metal chelates of dithiocarbazic acid and its derivatives. VII. The magnetism of some copper(II) complexes of salicylaldehyde Schiff bases derived from N-methyl-S-methyldithiocarbazate and S,S'-dimethyldithiocarbazate, Inorg. Chim. Acta. 1973; 7 : 531-537.

[4] Akbar Ali , M., Tarafder, M.T.H., Jalil miah, M.A. and Bose,R. N., Metal complexes of some schiff bases derived from s-benzyldithiocarbazate, J. Inorg. Nucl,Chem. 1981; 43: 3151-3157.

[5] Md. Tofazzal H. Tarafder, N. Saravanan, Karen A. Crouse, Abdul Manaf b. Ali., Coordination chemistry and biological activity of nickel(II) and copper(II) ion complexes with nitrogen-sulphur donor ligands derived from S-benzyldithiocarbazate (SBDTC), Transition Metal Chemistry. 2001; 26 (6): 613-618.

[6] Akbar Ali,M. and Tarafder, M.T.H., Metal complexes of sulphur and nitrogen-containing ligands: Complexes of s-benzyldithiocarbazate and a schiff base formed by its condensation with pyridine-2-carboxaldehyde J. Inorg Nucl,Chem. 1977 39,1785-1791.

[7] Akbar Ali, M., Hossain, G., Mazumder, S. M. M. H., Nazimuddin, M. and Tarafder, M.T.H., Synthesis and characterization of some new nickel(II), zinc(II) and cadmium(II) complexes of quadridentate SNNS ligands Polyhedron, 1987; 6: 1653-1656.

[8] Hazari, S. K. S., Palit, D., Dey, B. K. and Mazumder, J. L., Chittagong University studies, Part-II, 20(1), 53, 1996.

[9] Akbar Ali, M., Chowdhury D. A. and Nazimuddin, M., Fourand five-coordinate copper(II) complexes containing mixed ligands, Polyhedron, 1984; 3(5): 595-598.

[10] Laila Arjuman Banu, M.S.Islam, M.Abdul Alim Al-Bari and Md.Kudrat-E-Zahan, Synthesis and characterization with antibacterial, antifungal, cytotoxicity studies on the Co (II), $\mathrm{Ni}(\mathrm{II})$ AND $\mathrm{Cu}(\mathrm{II})$ complexes of tridentate ONO coordinating schiff bases and heterocyclic amines. Int. Jour. of Recent Adv. in Multi. Res. 2015; 02(01): 145-148.

[11] Md. Kudrat-E-Zahan, Md. Abul Bashar, Md. Faruk Hossen, and M. Saidul Islam. Synthesis, Spectroscopic, Magnetic and Biological Activity of $\mathrm{Cr}(\mathrm{III})$ and $\mathrm{Fe}(\mathrm{III})$ Complexes with Amino Acids and Heterocyclic Amines. Asian Jour. of Res. in Chem., 2015; 8(2): 74-76.

[12] Md. Abul Bashar, Md. Abdul Mannan, Md. Faruk Hossen, M. Saidul Islam and Md. Kudrat-E-Zahan. The synthesis, characterization and biological activity investigation of mixed ligand Coordinated Ni(II) Complexes. Asian Jour. of Res. in Chem, 2015; 8(1): 55-58.

[13] Md. Abdul Latif, Md. Anarul Islam and Md.Kudrat-E-Zahan, Synthesis, Structure andAntimicrobial studies of four new $\mathrm{N}_{2} \mathrm{O}_{4}$ schiff base containing complexes of $\mathrm{Ag}(\mathrm{I}), \mathrm{Cr}(\mathrm{III}), \mathrm{Fe}(\mathrm{III})$ and $\mathrm{Sb}(\mathrm{III})$ metal ions. Intern. Jour. of Recent Adv. in Multi. Res., 2015; 02(02): 206-208. 
[14] Md. Abul Bashar, Shejuty aktar, Md. Abdul Alim Al-Bari, Md. Faruk Hossen, M. Saidul Islam and Md. Kudrat-E-Zahan. Synthesis, Characterization and Antimicrobial Activity of Amino acids and Heterocyclic amines Coordinating $\mathrm{Cu}(\mathrm{II})$ Complexes. Asian Jour. of Res. in Chem, 2014; 7(11): 909-912.

[15] Md. Shiraj-U-Ddaula, Md. Anarul Islam, Shejuty aktar, Md. Khairul Islam, Md. Abdul Alim Al-Bari, Md. Masuqul Haque and Md.Kudrat-E-Zahan. Synthesis, Characterization and Antimicrobial activity of $\mathrm{Cd}(\mathrm{II}), \mathrm{Ni}(\mathrm{II}), \mathrm{Co}(\mathrm{II})$ and $\mathrm{Zr}(\mathrm{IV})$ metal complexes of Schiff base ligand derived from diethylenetriamine and isatin. Asian Jour. of Res. in Chem, 2014; 7(7): 619-621.

[16] Md. Abul Bashar, Shejuty aktar, Md. Jahangir Alam, Md. Faruk Hossen, M. Saidul Islam and Md. Kudrat-E-Zahan. Studies on synthesis, characterization and biological activity of mixed ligand Coordinating Co(II) Complexes. Asian Jour. of Res. in Chem, 2014; 7(12): 1016-1018.
[17] Md.Anarul Islam, Roksana khatun, M.Monirul Islam and Md.Kudrat-E-Zahan, Synthesis, spectroscopic monitoring and biological activities of $\mathrm{N} 2 \mathrm{O} 4$ schiff base ligand containing metal complexes of $\mathrm{Cd}(\mathrm{II}), \mathrm{Pd}(\mathrm{II}), \mathrm{Hg}(\mathrm{II})$ and $\mathrm{Zr}(\mathrm{IV})$. Asian Jour. of Res. in Chem, 2014; 7(2): 163-165.

[18] Md.Kudrat-E-Zahan and Hiroshi Sakiyama, Synthesis and spectral properties of dinuclear Bis(acetylacetonato)nickel(II)aqua complex, Asian Jour. of Res. in Chem, 2013; 6(11): 1072-1074.

[19] Md.Kudrat-E-Zahan, M. S. Islam and Md.Abul Bashar. Synthesis, Characterization and antimicrobial activity of Some Metal Complexes of $\mathrm{Mn}(\mathrm{II}), \mathrm{Fe}(\mathrm{III}) \mathrm{Co}(\mathrm{II}), \mathrm{Ni}(\mathrm{II}), \mathrm{Cu}(\mathrm{II})$ and $\mathrm{Sb}(\mathrm{III})$ Containing Bidentate Schiff base of SMDTC, Russ. Jour of gen. Chem. 2015; 85(3). 